\title{
Treatment of Cerebral Palsy with Stem Cells: A Report of 17 Cases
}

\author{
Nassim H. Abi Chahine ${ }^{1}$, Tarek W. Wehbe ${ }^{2}$, Ramzi A. Hilal ${ }^{3}$, \\ Victoria V. Zoghbi ${ }^{4}$, Alia E. Melki ${ }^{5}$, Emil B. Bou Habib ${ }^{6}$ \\ ${ }^{I}$ Neurosurgery, The Lebanese-Canadian Hospital, Beirut, Lebanon, ${ }^{2}$ Head of the Department of Hematology, \\ Notre Dame Du Liban University Hospital and The Lebanese-Canadian Hospital, Beirut, Lebanon, ${ }^{3}$ Neurology, Head of the \\ Department, The Lebanese-Canadian Hospital, Beirut, ${ }^{4}$ Anesthesiology and Reanimation, Salam Hospital, Tripoli, Lebanon \\ ${ }^{5}$ Doctorate of Acupuncture and TCM, The Five Elements Wellness Center, Koura, Lebanon \\ ${ }^{6}$ Neurosurgery, Head of Department, The Lebanese-Canadian Hospital, Beirut, Lebanon
}

Cerebral Palsy (CP) is a disabling condition that affects a child's life and his/her family irreversibly. It is usually a non-progressive condition but improvement over time is rarely seen. The condition can be due to prenatal hypoxia, metabolic, genetic, infectious, traumatic or other causes. It is therefore a heterogeneous group that results in functional motor disability associated with different degrees of cognitive abnormalities. There are no treatments that can cure or even improve $\mathrm{CP}$ and the best available approach aims at functional, social and nutritional supportive care and counseling. In this paper, we report 17 sequential patients with $\mathrm{CP}$ treated with intrathecal administration of Bone Marrow Mononuclear Cells (BMMC). All patients had an uneventful post-injection course with 73\% of the evaluable patients treated having a good response using the Gross Motor Function Classification System (GMFCS). The average improvement was 1.3 levels on the GMFCS with cognitive improvements as well.

Keywords: Stem cells, Bone Marrow Mononuclear Cells, Cerebral palsy, Intrathecal injection

\section{Introduction}

Cerebral Palsy is a heterogeneous group of conditions that results in permanent, non-progressive motor disability. It may be due to perinatal hypoxic insults, developmental brain abnormalities, genetic conditions, traumatic or infectious causes. The insults may occur at any time during gestation resulting in variations in the clinical

\footnotetext{
Accepted for publication January 19, 2016, Published online May 30, 2016 Correspondence to Nassim H. Abi Chahine

Neurosurgery, The Lebanese-Canadian Hospital, Sin El Fil, Horch Tabet, Beirut, Lebanon

Tel: +961-308-2498, Fax: +961-695-1100

E-mail: nassim@wp.eu

(c) This is an open-access article distributed under the terms of the Creative Commons Attribution Non-Commercial License (http://creativecommons.org/ licenses/by-nc/4.0/), which permits unrestricted non-commercial use, distribution, and reproduction in any medium, provided the original work is properly cited.
}

patterns observed. The consequence is a major burden on the patient and family socially and financially $(1,2)$.

It is estimated that about 2 per 1,000 babies are born each year with CP. Improvements in the neonatal care had little or no effect to date on this incidence. There are several classifications used for $\mathrm{CP}$ depending on different elements of the motor function. The Gross Motor Function Classification System (GMFCS) detailed below is adjusted to age and reflects the degree of independent activities and functions. Another way to describe and classify CP is by the number of affected limbs (e.g. hemiplegia, hemiparesis, quadreparesis, etc.) $(3,4)$. A third method is based on the presence or absence of spasticity, coordination, and the muscle tone. Spastic hypertonic, or non-spastic, pyramidal or non-pyramidal based on the patient coordination. This description usually reflects the site and degree of pathology. The non-spastic, pyramidal type can be further classified as ataxic or dyskinetic types $(5,6)$. 
In addition to these types and descriptions there are cases with mixed manifestations involving several features described above in associations with other elements like Autism. This variety reflects the extent and variability of the pathobiology involving different areas of the central nervous system and makes it very difficult to study a real homogeneous group of subjects $(7,8)$.

This debilitating disease seemed a logical target for stem cell therapy to repair the neurologic defects, stimulate the endogenous stem cells to repair and regenerate and reestablish the lost balance between the different neurotrophic factors (9-13). The aim of this study is to find out, using a scientific phase II design, whether injecting concentrated BMMCs intrathecally once would help improve cerebral palsy motor and cognitive functions as assessed by standardized tools described below.

\section{Stem Cell Therapy}

Stem cells are multipotent progenitor cells that have been shown to have regenerative as well as imunomodulatory and growth stimulating properties. They have been shown in vitro to have the capacity to induce angiogenesis and differentiate into different types of cells including cells of the nervous system (14-16).

There are several types of stem cells in clinical use or clinical trials. These include the hematopoietic stem cells, the Bone Marrow Mononuclear cells (BMMC) which include the hematopoietic and mesenchymal cells found in the bone marrow in small numbers (MSCs), very small embryonic like stem cells, and endothelial precursor cells among others. Furthermore, MSCs can be sequentially cultured in specially defined conditions exploiting their attachment to the culture dish. Mesenchymal stem cells have been shown to be safe in certain conditions. They are being explored as well for new applications such as tissue engineering and gene therapy $(17,18)$.

The third type of cells gaining favor in clinical studies is the Neural Stem Cells (NSCs) especially targeted for neurologic diseases like Amyotrophic Lateral Sclerosis (ALS) and spinal cord injuries. Furthermore, new clinical methods aiming at manipulating the stem cells or combining them with other types of treatments like plasmapheresis, rituximab, different growth factors, or other therapies appear to be safe and potentially effective $(19,20)$.

Chaitinya et al. used autologous bone-marrow-derived mononuclear cell (BMMNCs) to treat one patient with CP. Giving the cells as five injections intrathecally, they reported improvements in the Gross Motor Function Classification System (GMFCS) scale, with marked motor, sensory, cognitive, and speech amelioration. They also reported better bowel and bladder control with excellent tolerance (21).

Konstantinos I. Papadopoulos et al. reported on 2 Thai children with cerebral palsy treated with autologous umbilical cord blood (UCB) cells and low dose Granulocyte Colony Stimulating Factor (GCSF) injections. The children tolerated the procedure well and showed significant improvement on the GMFCS without any significant side effects (22).

The BMMCs may generate neurons, counteract fibrosis and oxidation (23). The BMMCs were considered for several reasons including some of the published data on their differentiation potential, safety and efficacy $(21,22)$ and our technical capabilities to collect them, separate them and prepare them for injection using sterile methodologies.

\section{Patients and Methods}

Seventeen patientswith CP were treated sequentially with BMMCs. The patients were included if they had CP confirmed by two neurologists and no significant cardiac, renal or hepatic impairments. The guardian(s) signed an imformed consent form after full explanation of the procedure and the safety issues involved. The patients were evaluated based on the GMFCS according to their motor skills and their cognitive skills before and after the treatment. The study was reviewed and approved by the scientific committee and IRB at the hospital.

On the day of the procedure, the bone marrow was collected under strict sterile conditions in the operating room under general anesthesia. two to five milliliters per $\mathrm{kg}$ of marrow were collected from the anterior or posterior iliac crests depending on the patient posture and contractures. Six to eight puncture sites were used to aspirate the bone marrow. The marrow was aspirated using a twenty $\mathrm{ml}$ syringe with citrate or heparin sodium as anticoagulants in a $10 \%$ solution. The BMMCs were collected and then washed and separated using the density gradient centrifugation method before counting the cells using the Neubauer chamber. The cells were subjected to microbiologic, microscopic, and serologic testing to characterize them, and secure their safety. The resulting cells were re-suspended to prepare the $5 \sim 10 \mathrm{ml} \mathrm{BMMC}$ to be injected.

The injected cells were adjusted to two million cells per kilogram of body weight $\pm 10 \%$. The patients were injected intrathecally once at the L4 L5 level under sterile conditions and under sedation in the operating room to secure accuracy and sterility. 


\section{Assessment tool}

Our goal for the assessment was to perform it every month as much as possible. There was, however, a problem in many cases due to the children status and a number of missed visits that we tried to make up for as best suitable for the child and family. In some cases, the patients travelled from different countries and we had to rely on the local neurologists and parent reports over the phone. The Gross Motor Function Classification system (GMFCS) is an assessment tool based on the motor function initially developed in 1997 and then revised in 2007. It uses 5 levels describing the motor function limitations and taking into consideration age, the use of mobility aids and the quality of movement $(24,25)$.

Levels 1 5 of the GMFCS describe worse dysfunctions and less dependence during mobility as the level goes up. Levels 1 and 2 have almost independent mobiliy while level 3 can move with assistive devices and levels 4 and 5 are significantly limited and dependent on their helpers for minor movements.

The environment and other personal factors have to be taken into consideration when making this assessment.

The assessment of the cognitive functions was done in a subjective manner with reliance mainly on the vocabulary used, understanding of spoken sentences in simple and complex formats. The assessment was done with the care taker and primary care physician when possible.

\section{Results}

Seventeen patients with CP aged 1.5 to 17 years were enrolled in this study, the motor function was hypotonic in 5 (29\%), Hypertonic in 8 (47\%), Dyskinetic in $2(11.7 \%)$, with choreoathetoid movements, one patient had dystonia, and one had mixed type. All patients data could be analyzed for safety. The average age was 6.5 years and a median of 6 years of age. The majority were males (14 of 17, or $82 \%$ ), and the female were 3 of 17 (18\%). Table 1 sum-

Table 2. Adverse events

\begin{tabular}{cl}
\hline Number & Adverse events \\
\hline 1 & Vomiting \\
2 & Headaches \\
3 & None \\
4 & None \\
5 & None \\
6 & None \\
7 & None \\
8 & Vomiting \\
9 & None \\
10 & Headaches \\
11 & None \\
12 & None \\
13 & None \\
14 & None \\
15 & None \\
16 & None \\
17 & Fever \\
\hline
\end{tabular}

Table 1. Patient Characteristics

\begin{tabular}{|c|c|c|c|c|}
\hline Number & Age & Gender & СР Type & PRE- GMFCS \\
\hline 1 & 3 & M & Dystonic & 5 \\
\hline 2 & 2 & M & Hypotonic & 5 \\
\hline 3 & 3.4 & M & Hypertonic & 4 \\
\hline 4 & 6 & $\mathrm{~F}$ & Hypertonic & 2 \\
\hline 5 & 2 & M & Hypotonic & 5 \\
\hline 6 & 17 & M & Hypotonic-Autistic & 1 \\
\hline 7 & 1.5 & M & Hypertonic & 4 \\
\hline 8 & 15 & M & Dyskinetic Choreoathetoid & 2 \\
\hline 9 & 9 & M & Hypertonic & 5 \\
\hline 10 & 8 & $\mathrm{~F}$ & Hypertonic & 5 \\
\hline 11 & 4 & M & Hypertonic & 4 \\
\hline 12 & 10 & $\mathrm{~F}$ & Dyskinetic Choreoathetoid & 2 \\
\hline 13 & 9 & M & Mixed & 5 \\
\hline 14 & 4 & M & Hypertonic & 5 \\
\hline 15 & 5 & M & Hypotonic-Autistic & 5 \\
\hline 16 & 6 & M & Hypertonic & 4 \\
\hline 17 & 5 & $M$ & Hypotonic & 5 \\
\hline
\end{tabular}


Table 3. Summary of the results

\begin{tabular}{|c|c|c|c|c|}
\hline Number & PRE- GMFCS & POST- GMFCS & Cognitive changes & Spasicity changes \\
\hline 1 & 5 & 4 & No change & No change \\
\hline 2 & 5 & 5 & No change & No change \\
\hline 3 & 4 & 2 & No change & No change \\
\hline 4 & 2 & 2 & No change & No change \\
\hline 5 & 5 & - & No change & - \\
\hline 6 & 1 & 0 & No change & No change \\
\hline 7 & 4 & 3 & Improved & Improved \\
\hline 8 & 2 & 2 & Improved & Improved \\
\hline 9 & 5 & 5 & No change & No change \\
\hline 10 & 5 & 4 & No change & No change \\
\hline 11 & 4 & 3 & Improved & Improved \\
\hline 12 & 2 & 1 & No change & No change \\
\hline 13 & 5 & 4 & Improved & Improved \\
\hline 14 & 5 & - & - & - \\
\hline 15 & 5 & 2 & Improved & Improved \\
\hline 16 & 4 & 2 & Improved & Improved \\
\hline 17 & 5 & 4 & No change & No change \\
\hline
\end{tabular}

marizes the demographic data of these patients.

The adverse events reported (Table 2) were limited to mild headaches ( 2 or $12 \%$ ), transient fever (1 or $6 \%$ ) or vomiting ( 2 or $12 \%$ ), or no reports of any adverse events (12 or 70\%). All side effects resolved within few days. No reports of seizures, agitation, meningitis, injection site pain or other serious events were noted.

The efficacy of the stem cell therapy and pre and post injection follow ups was available for 15 evaluable patients (Table 3). Eleven of the 15 had a significant improvement (73\%). The improvement ranged from 1 to 3 levels on the GMFCS scoring system. The average improvement was 1.3 points with a range of 0 to 3 points of improvement with no patients showing regression. The improvement was most pronounced in the degree of spasticity in 6 patients (40\%) and in many cases it was the first feature noted to improve. Some families reported bowel and bladder control improvement along with the motility and independent activity. The cognitive function assessment also revealed significant improvement in 6 of the 15 patients (40\%). The assessment was performed with the help of the care givers and the patient's primary physicians. The results are summarized in Table 3.

Even though not everypatient improved, overall, the majority of patients showed significant improvements in situations that were hopeless. Some patient functional improvement was significant and they improved to a point of becoming somewhat independent (4 of 15, or 27\%).

Analysis of our data shows that improvement did not correlate with the age of the patients, type or severity of
$\mathrm{CP}$ although the number of the patients is too small to make such conclusions confidently.

\section{Discussion}

Cerebral palsy is a debilitating condition to the child and poses unusual burdens on the family and the society. It is the costliest among the congenital diseases because it requires the use of several medical and social resources (2). Any scientific trial looking to draw useful conclusions should aim at a target population that is as homogeneous as possible in order to come up with reliable data. It is also crucial to use validated assessment tools like the GMFCS with a long term follow up and periodic assessments to understand the short and long term benefits and risks involved (26-28). Unfortunately, not all these elements were available to us and not all patients had long follow up periods for several reasons including travel, cultural and financial issues.

There are likely several effective mechanisms of action involved, including regeneration of the neural cells, direct stimulation of the neurons, the endogenous stem cells as well as neovascularization and trophic paracrine mediators. There are only some animal data to illuminate the mechanisms of the stem cell actions in vivo and no significant postmortum data to further improve our understanding at this point in time (29-31).

Growth factors like G-CSF, Stem Cell Factor (SCF), the fibroblast growth factor (FGF) and othersmay reduce the volume of ischemia and increase migrationand prolifera- 
tion of the stem cells. The bone marrowendothelial precursors may also improve angiogenesis up to 2 months post insult. There is evidence that the growth factors like the ones released from the stem cells may help improve brain regeneration (32-34).

The BMMCs may generate neurons and other supportive cells. Transplanted bone marrow cells infiltrate the brain and may help regenerate new elements or combat the neurodegenerative process, fibrosis and oxidative insults. The result is potential repair of the damaged tissues (23). Neuroprotection may involve release of several neurotrophic factors, that work through paracrine and/orautocrine interactions (35).

Sharma et al reported an amazing $85 \%$ improvement among cerebral palsy cases, out of which $75 \%$ reported improvement in muscle tone and 50\% in speech among other symptoms. No significant adverse events were noted. There was significant improvement of the quality of life as well (36).

\section{Conclusions}

Our report shows the safety and efficacy of bone marrow mononuclear cells (BMMCs) injected intrathecally once to patients with different types of CP. The injections could be repeated theoretically to continue the improvement or add to it over time should the patient benefit from this approach. It is not clear at this time what is the best number of injections, the injection schedule, whether it is beneficial to add growth factors to maximize this effect. Our data shows that about $73 \%$ of patients with CP may benefit from this treatment. The improvement ranges from 0 to 3 score levels averaging 1.3 points. There is also agood degreeof cognitive, functional, and bladder and bowel control as well as improvement of the spasticity. The treatment has to be complemented by rigorous physical and cognitive stimulation. It is very interesting to watch for the results of the MSCs and neural stem cells in this disease as well as the different protocols using different injection schedule or adding growth factors, neurostimulation and other promising therapies.

\section{References}

1. Spencer NJ, Blackburn CM, Read JM. Disabling chronic conditions in childhood and socioeconomic disadvantage: a systematic review and meta-analyses of observational studies. BMJ Open 2015;5:e007062

2. My Child at CerebralPalsy.org [Internet]. 2015 Oct. Available from: http://cerebralpalsy.org/about-cerebral-palsy/costs/.
3. Andersen GL, Irgens LM, Haagaas I, Skranes JS, Meberg AE, Vik T. Cerebral palsy in Norway: prevalence, subtypes and severity. Eur J Paediatr Neurol. 2008;12:4-13

4. Cauraugh JH, Naik SK, Hsu WH, Coombes SA, Holt KG. Children with cerebral palsy: a systematic review and meta-analysis on gait and electrical stimulation. Clin Rehabil 2010;24:963-978

5. Bax M, Goldstein M, Rosenbaum P, Leviton A, Paneth N, Dan B, Jacobsson B, Damiano D; Executive Committee for the Definition of Cerebral Palsy. Proposed definition and classification of cerebral palsy, April 2005. Dev Med Child Neurol 2005;47:571-576

6. Driscoll SW, Skinner J. Musculoskeletal complications of neuromuscular disease in children. Phys Med Rehabil Clin N Am 2008;19:163-194

7. Christensen D, Van Naarden Braun K, Doernberg NS, Maenner MJ, Arneson CL, Durkin MS, Benedict RE, Kirby RS, Wingate MS, Fitzgerald R, Yeargin-Allsopp M. Prevalence of cerebral palsy, co-occurring autism spectrum disorders, and motor functioning - Autism and Developmental Disabilities Monitoring Network, USA, 2008. Dev Med Child Neurol 2014;56:59-65.

8. Shevell MI, Dagenais L, Hall N; REPACQ CONSORTIUM. The relationship of cerebral palsy subtype and functional motor impairment: a population-based study. Dev Med Child Neurol 2009;51:872-877

9. Nishio Y, Koda M, Kamada T, Someya Y, Kadota R, Mannoji C, Miyashita T, Okada S, Okawa A, Moriya H, Yamazaki M. Granulocyte colony-stimulating factor attenuates neuronal death and promotes functional recovery after spinal cord injury in mice. J Neuropathol Exp Neurol 2007;66:724-731

10. Serefhanoglu S, Goker H, Buyukasik Y, Turgut $M$, Sayinalp N, Haznedaroglu IC, Aksu S, Akman U, Ozcebe OI. Changes in vascular endothelial growth factor, angiopoietins, and Tie-2 levels with G-CSF stimulation in healthy donors. Ann Hematol 2009;88:667-671

11. Haynes RL, Xu G, Folkerth RD, Trachtenberg FL, Volpe JJ, Kinney HC. Potential neuronal repair in cerebral white matter injury in the human neonate. Pediatr Res 2011;69: 62-67

12. Fancy SP, Harrington EP, Yuen TJ, Silbereis JC, Zhao C, Baranzini SE, Bruce CC, Otero JJ, Huang EJ, Nusse R, Franklin RJ, Rowitch DH. Axin2 as regulatory and therapeutic target in newborn brain injury and remyelination. Nat Neurosci 2011;14:1009-1016

13. O'Shea TM, Allred EN, Dammann O, Hirtz D, Kuban KC, Paneth N, Leviton A; ELGAN study Investigators. The ELGAN study of the brain and related disorders in extremely low gestational age newborns. Early Hum Dev 2009;85:719-725

14. Najm FJ, Zaremba A, Caprariello AV, Nayak S, Freundt EC, Scacheri PC, Miller RH, Tesar PJ. Rapid and robust generation of functional oligodendrocyte progenitor cells from epiblast stem cells. Nat Methods 2011;8:957-962

15. Lee YH, Choi KV, Moon JH, Jun HJ, Kang HR, Oh SI, 
Kim HS, Um JS, Kim MJ, Choi YY, Lee YJ, Kim HJ, Lee JH, Son SM, Choi SJ, Oh W, Yang YS. Safety and feasibility of countering neurological impairment by intravenous administration of autologous cord blood in cerebral palsy. J Transl Med 2012;10:58

16. Meier C, Middelanis J, Wasielewski B, Neuhoff S, RothHaerer A, Gantert M, Dinse HR, Dermietzel R, Jensen A. Spastic paresis after perinatal brain damage in rats is reduced by human cord blood mononuclear cells. Pediatr Res 2006;59:244-249

17. García-Olmo D, García-Arranz M, Herreros D, Pascual I, Peiro C, Rodríguez-Montes JA. A phase I clinical trial of the treatment of Crohn's fistula by adipose mesenchymal stem cell transplantation. Dis Colon Rectum 2005;48:14161423

18. Le Blanc K, Rasmusson I, Sundberg B, Götherström C, Hassan $M$, Uzunel $M$, Ringdén $O$. Treatment of severe acute graft-versus-host disease with third party haploidentical mesenchymal stem cells. Lancet 2004;363:1439-1441

19. Thomsen GM, Gowing G, Svendsen S, Svendsen CN. The past, present and future of stem cell clinical trials for ALS. Exp Neurol 2014;262 Pt B:127-137

20. Andressen C. Neural stem cells: from neurobiology to clinical applications. Curr Pharm Biotechnol 2013;14:20-28

21. Purandare C, Shitole DG, Belle V, Kedari A, Bora N, Joshi M. Therapeutic potential of autologous stem cell transplantation for cerebral palsy. Case Rep Transplant 2012; 2012:825289

22. Papadopoulos KI, Low SS, Aw TC, Chantarojanasiri T. Safety and feasibility of autologous umbilical cord blood transfusion in 2 toddlers with cerebral palsy and the role of low dose granulocyte-colony stimulating factor injections. Restor Neurol Neurosci 2010;28:1-6

23. Wang M, Yang Y, Yang D, Luo F, Liang W, Guo S, Xu J. The immunomodulatory activity of human umbilical cord blood-derived mesenchymal stem cells in vitro. Immunology 2009;126:220-232

24. Palisano R, Rosenbaum P, Walter S, Russell D, Wood E, Galuppi B. Development and reliability of a system to classify gross motor function in children with cerebral palsy. Dev Med Child Neurol. 1997;39:214-223

25. Palisano RJ, Cameron D, Rosenbaum PL, Walter SD, Russell D. Stability of the gross motor function classification system. Dev Med Child Neurol 2006;48:424-428

26. Shyu WC, Lin SZ, Lee CC, Liu DD, Li H. Granulocyte colony-stimulating factor for acute ischemic stroke: a randomized controlled trial. CMAJ 2006;174:927-933

27. Schäbitz WR, Krüger C, Pitzer C, Weber D, Laage R, Gassler N, Aronowski J, Mier W, Kirsch F, Dittgen T, Bach
A, Sommer C, Schneider A. A neuroprotective function for the hematopoietic protein granulocyte-macrophage colony stimulating factor (GM-CSF). J Cereb Blood Flow Metab 2008;28:29-43

28. Sevimli S, Diederich K, Strecker JK, Schilling M, Klocke R, Nikol S, Kirsch F, Schneider A, Schäbitz WR. Endogenous brain protection by granulocyte-colony stimulating factor after ischemic stroke. Exp Neurol 2009;217:328-335

29. Arien-Zakay H, Lecht S, Bercu MM, Tabakman R, Kohen R, Galski H, Nagler A, Lazarovici P. Neuroprotection by cord blood neural progenitors involves antioxidants, neurotrophic and angiogenic factors. Exp Neurol 2009;216:83-94

30. Tigue CC, McKoy JM, Evens AM, Trifilio SM, Tallman MS, Bennett CL. Granulocyte-colony stimulating factor administration to healthy individuals and persons with chronic neutropenia or cancer: an overview of safety considerations from the Research on Adverse Drug Events and Reports project. Bone Marrow Transplant 2007;40:185-192

31. Kuban JL, Hecht AB, Onderdonk T, Michael O'Shea N. Understanding the underlying beneficial biology of stem cells and the development and validation of more relevant animal models is required. Paneth Pediatr Res 2010;67: 95-101

32. Welte K, Platzer E, Lu L, Gabrilove JL, Levi E, Mertelsmann R, Moore MA. Purification and biochemical characterization of human pluripotent hematopoietic colony-stimulating factor. Proc Natl Acad Sci U S A 1985;82:1526-1530

33. Toth ZE, Leker RR, Shahar T, Pastorino S, Szalayova I, Asemenew B, Key S, Parmelee A, Mayer B, Nemeth K, Bratincsák A, Mezey E. The combination of granulocyte colony-stimulating factor and stem cell factor significantly increases the number of bone marrow-derived endothelial cells in brains of mice following cerebral ischemia. Blood 2008;111:5544-5552

34. Mezey E, Key S, Vogelsang G, Szalayova I, Lange GD, Crain B. Transplanted bone marrow generates new neurons in human brains. Proc Natl Acad Sci U S A 2003;100:13641369

35. Wang L, Ji H, Zhou J, Xie J, Zhong Z, Li M, Bai W, Li N, Zhang Z, Wang X, Zhu D, Liu Y, Wu M. Therapeutic potential of umbilical cord mesenchymal stromal cells transplantation for cerebral palsy: a case report. Case Rep Transplant 2013;2013:146347

36. Sharma A, Gokulchandran N, Chopra G, Kulkarni P, Lohia M, Badhe P, Jacob VC. Administration of autologous bone marrow-derived mononuclear cells in children with incurable neurological disorders and injury is safe and improves their quality of life. Cell Transplant 2012;21 Suppl 1:S79-S90 